\title{
3-Ethyl-4-amino-5-mercapto-1,2,4-triazole as Corrosion Inhibitor for 6061-Alloy in Sodium Hydroxide Solution
}

\author{
P.D. Reena Kumari, ${ }^{1}$ Jagannath Nayak, ${ }^{2}$ A. Nityananda Shetty ${ }^{*}, 1$ \\ ${ }^{1}$ Department of Chemistry, National Institute of Technology Karnataka Surathkal, Mangalore, \\ Karnataka State-575 025, India \\ ${ }^{2}$ Department of Metallurgical \& Materials Engineering, National Institute of Technology \\ Karnataka Surathkal, Mangalore, Karnataka State-575 025, India
}

Received 13 October 2010; accepted 27 October 2011

\begin{abstract}
The inhibition action of 3-ethyl-4-amino-5-mercapto-1,2,4-triazole (EAMT) on the corrosion of 6061-Al alloy in different concentrations of aqueous sodium hydroxide solution has been investigated at different temperatures, using potentiodynamic polarization and electrochemical impedance spectroscopic techniques. The surface morphology of the metal surface was investigated by scanning electron microscopy (SEM). The experimental results showed that the presence of EAMT in sodium hydroxide solution decreases the corrosion rates and the corrosion current densities $\left(i_{\text {corr }}\right)$, and increases the charge transfer resistance $\left(R_{\mathrm{p}}\right)$. It was found that the inhibitor efficiency depends on the concentration of the inhibitor, concentration of the corrosive media and temperature. The inhibition was assumed to occur through adsorption of the inhibitor molecule on the metal surface. The adsorption of the inhibitor on the metal surface is found to obey Langmuir adsorption isotherm. EAMT acts as a mixed inhibitor. Thermodynamic parameters for the adsorption processes were determined from the experimental data. The results obtained from both the techniques are in good agreement.
\end{abstract}

Keywords: 6061/Al alloy, corrosion inhibitor, triazole derivative, electrochemical techniques, adsorption isotherm.

\section{Introduction}

6061-Al alloy is one of the most extensively used of the 6000 series aluminium alloys, widely used for the construction of aircraft structures, yacht, bicycle frames, machinery and process-equipment applications. 6061-Al alloy, containing magnesium and silicon as its major alloying elements, is a versatile

\footnotetext{
* Corresponding author. E-mail address: nityashreya@gmail.com
} 
heat treatable alloy with medium to high strength capabilities; satisfies the requirements of a number of specifications in extruded shape. Owing to its wide applicability in industrial and every day life, the electrochemical properties of aluminium and its alloys are the subject of many studies [1-7]. However, corrosion is indeed one of the major problems affecting the performance and safety of the metal. Several methods have been devised for preventing or reducing corrosion, which include coating, painting, as well as the use of chemical inhibitors. The use of some organic and inorganic compounds as effective inhibitors to protect metallic materials in the environment containing aggressive ions has been reported. It has been reported that many organic compounds containing hetero atoms like $\mathrm{N}, \mathrm{O}, \mathrm{S}$, and multiple bonds in their molecules have been proved to be effective inhibitors for the corrosion of aluminium alloys in acid and alkaline media [8-15]. Generally, it has been assumed that the action of inhibitors in aggressive media is by the adsorption of the inhibitors onto the metal surface. The processes of adsorption of the inhibitor are influenced by the nature and surface charge of the metal, the chemical structure of organic inhibitors, the type of aggressive electrolyte and the type of interaction between the organic molecules and the metallic surface [16]. The purpose of the present contribution is to determine the influence of 3-ethyl-4amino-5-mercapto-1,2,4-triazole (EAMT) towards the corrosion of $6061 \mathrm{Al}$ alloy in sodium hydroxide solution, using potentiodynamic polarization and electrochemical impedance techniques. It is aimed at obtaining the information about surface morphology of the corroded base alloy metal surface by using SEM. It was also the purpose of this work to determine the thermodynamic parameters for the adsorption process and to gain more information about the mode of adsorption of the inhibitor on the metal surface.

\section{Experimental}

\section{Materials and chemicals}

The material employed was 6061-Al alloy in the extruded rod form (extrusion ratio 30:1). The chemical composition of the base metal 6061 aluminium alloy is given in Table 1. The sample was metallographically mounted up to $10 \mathrm{~mm}$ height using cold setting epoxy resin, so that the exposed surface area of the metal to the media was $0.785 \mathrm{~cm}^{2}$. The sample was mechanically polished using different emery papers up to 4/0 grades and finally polished on polishing wheel using levigated alumina. Then it was cleaned with acetone, washed with doubly distilled water and finally dried. For the electrochemical measurement the arrangement used was a conventional three electrode Pyrex glass cell with a platinum counter electrode and a saturated calomel electrode (SCE) as reference.

Table 1. Chemical composition of 6061-Al alloy.

\begin{tabular}{cccccc}
\hline Element & $\mathrm{Cu}$ & $\mathrm{Si}$ & $\mathrm{Mg}$ & $\mathrm{Cr}$ & $\mathrm{Al}$ \\
\hline Composition (wt\%) & 0.25 & 0.6 & 1.0 & 0.25 & Balance \\
\hline
\end{tabular}


The test solution used for the investigation was standard solutions of sodium hydroxide prepared by using sodium hydroxide pellets of AR grade and double distilled water.

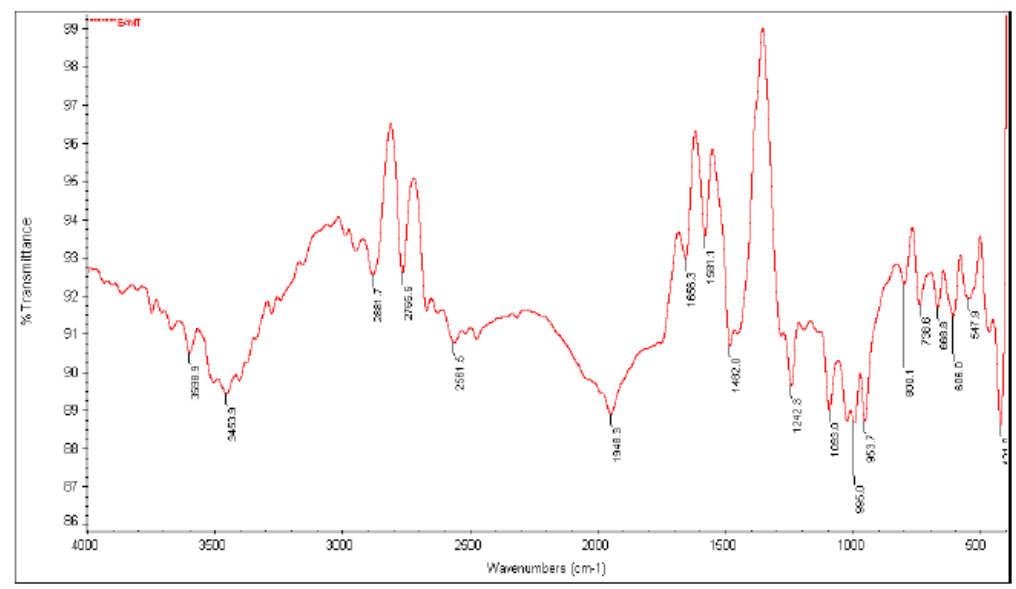

Figure 1. IR spectrum of 3-ethyl-4-amino-5-mercapto-1,2,4-triazole.

\section{Synthesis of EAMT}

3-ethyl-4-amino-5-mercapto-1,2,4-triazole was synthesized and recrystallised as per the reported procedure [17]. A mixture of thiocarbohydrazide $(10 \mathrm{~g})$ and propionic acid $(60 \mathrm{~mL})$ was heated, under reflux for 4 hours. The product was recrystallised from ethanol and characterized by IR (Fig. 1), elemental analysis and melting point. Fig. 2 shows the molecular structure of EAMT.

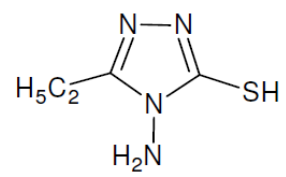

Figure 2. The molecular structure of 3-ethyl-4-amino-5-mercapto-1,2,4-triazole.

\section{Potentiodynamic polarization method}

Electrochemical measurements were carried out by using an electrochemical work station, GillAC and ACM Instruments Version 5 software. Tafel plot measurements were carried out using a conventional three electrode Pyrex glass cell with a platinum counter electrode and a saturated calomel electrode (SCE) as reference electrode. All the potential values are, therefore, referred to the SCE. Finely polished alloy specimens were exposed to corrosion medium of different concentrations of sodium hydroxide at different temperatures $\left(30{ }^{\circ} \mathrm{C}\right.$ to $\left.50{ }^{\circ} \mathrm{C}\right)$ and allowed to establish a steady state open circuit potential for 10 minutes. The potentiodynamic current-potential curves were recorded by polarizing the specimen to $-250 \mathrm{mV}$ cathodically and to $+250 \mathrm{mV}$ anodically with respect to the open circuit potential (OCP) at a scan rate of $1 \mathrm{mVs}^{-1}$. 


\section{Electrochemical impedance spectroscopy studies (EIS)}

The corrosion behavior of the specimens of the base alloy was also obtained from EIS technique using the work station, GillAC. In EIS technique a small amplitude ac signal of $10 \mathrm{mV}$ and frequency spectrum from $100 \mathrm{kHz}$ to $0.01 \mathrm{~Hz}$ was impressed at the OCP. A steady state open circuit potential was obtained for 10 minutes, and the impedance data were analyzed using Nyquist plots. The polarization resistance, $R_{\mathrm{p}}$, was extracted from the diameter of the semicircle in the Nyquist plot.

In all the above measurements, at least three similar results were considered and their average values are reported.

\section{Scanning electron microscopy (SEM) analysis}

The scanning electron microscope images of the samples were recorded using a JEOL JSM - 6380 LA analytical scanning electron microscope.

\section{Results and discussion}

\section{Potentiodynamic polarization method}

The polarization studies of the base alloy specimens were carried out in four different solutions containing $0.05 \mathrm{M}, 0.1 \mathrm{M}, 0.25 \mathrm{M}$ and $0.5 \mathrm{M}$ sodium hydroxide, in the absence and in the presence of different concentrations of EAMT $(5-100 \mathrm{ppm})$. Fig. 3 shows the Tafel polarization curves of the base alloy in $0.5 \mathrm{M} \mathrm{NaOH}$ solution at $30^{\circ} \mathrm{C}$ in the presence of different concentrations of EAMT. Similar results were obtained in the same concentration of sodium hydroxide at four other temperatures, and also in the other three concentrations of sodium hydroxide at the five temperatures studied. The electrochemical parameters $\left(\mathrm{E}_{\mathrm{corr}}, \mathrm{i}_{\mathrm{corr}}, \mathrm{b}_{\mathrm{a}}, \mathrm{b}_{\mathrm{c}}\right.$, and \%IE) associated with the polarization measurements at different EAMT concentrations as well as at different concentrations of the corrosion media for the base alloy are listed in Table 2 .

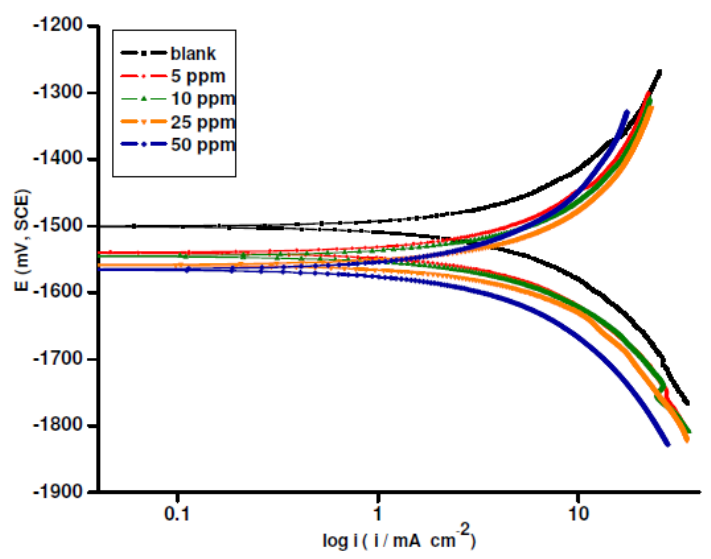

Figure 3. Tafel plots for the corrosion of 6061-Al alloy in $0.5 \mathrm{M}$ sodium hydroxide solution containing various concentrations of EAMT at $30^{\circ} \mathrm{C}$. 
Table 2. Results of the Tafel polarization studies for the corrosion of 6061-Al alloy at $30{ }^{\circ} \mathrm{C}$ in the presence of EAMT at different concentrations of $\mathrm{NaOH}$ solutions.

\begin{tabular}{|c|c|c|c|c|c|c|}
\hline $\begin{array}{c}\mathrm{NaOH} \\
\text { concentration } \\
\left(\text { mole } \mathrm{dm}^{-3}\right) \\
\end{array}$ & $\begin{array}{c}\text { Inhibitor } \\
\text { concentration } \\
(\mathrm{ppm})\end{array}$ & $\begin{array}{c}E_{\text {corr }} \\
(\mathrm{V} / \mathrm{SCE})\end{array}$ & $\begin{array}{c}b_{\mathrm{a}} \\
\left(\mathrm{mV} \operatorname{dec}^{-1}\right)\end{array}$ & $\begin{array}{c}-b_{\mathrm{c}} \\
\left(\mathrm{mV} \mathrm{dec}{ }^{-1}\right)\end{array}$ & $\begin{array}{c}i_{\text {corr }} \\
\left(\mathrm{mA} \mathrm{cm}^{-2}\right)\end{array}$ & $\operatorname{IE}(\%)$ \\
\hline \multirow{7}{*}{0.05} & 0 & -1.476 & 265 & 233 & 0.676 & - \\
\hline & 5 & -1.494 & 263 & 238 & 0.579 & 14.4 \\
\hline & 10 & -1.503 & 260 & 232 & 0.544 & 19.5 \\
\hline & 25 & -1.508 & 254 & 229 & 0.481 & 28.8 \\
\hline & 50 & -1.507 & 244 & 204 & 0.441 & 34.8 \\
\hline & 60 & -1.503 & 204 & 192 & 0.499 & 26.2 \\
\hline & 100 & -1.499 & 206 & 198 & 0.524 & 22.5 \\
\hline \multirow{7}{*}{0.1} & 0 & -1.475 & 237 & 226 & 1.254 & - \\
\hline & 5 & -1.509 & 207 & 175 & 1.037 & 17.3 \\
\hline & 10 & -1.511 & 204 & 180 & 0.994 & 20.7 \\
\hline & 25 & -1.517 & 206 & 178 & 0.882 & 29.7 \\
\hline & 50 & -1.518 & 143 & 136 & 0.731 & 41.2 \\
\hline & 60 & -1.516 & 160 & 149 & 0.817 & 34.8 \\
\hline & 100 & -1.525 & 176 & 162 & 0.886 & 29.3 \\
\hline \multirow{7}{*}{0.25} & 0 & -1.486 & 223 & 220 & 2.342 & - \\
\hline & 5 & -1.558 & 189 & 184 & 1.907 & 18.6 \\
\hline & 10 & -1.562 & 192 & 153 & 1.756 & 25.0 \\
\hline & 25 & -1.540 & 171 & 147 & 1.386 & 40.8 \\
\hline & 50 & -1.548 & 218 & 165 & 1.328 & 43.3 \\
\hline & 60 & -1.553 & 108 & 106 & 1.445 & 38.3 \\
\hline & 100 & -1.550 & 112 & 106 & 1.546 & 34.0 \\
\hline \multirow{7}{*}{0.5} & 0 & -1.501 & 313 & 289 & 5.574 & - \\
\hline & 5 & -1.539 & 289 & 241 & 3.557 & 36.2 \\
\hline & 10 & -1.545 & 276 & 233 & 3.479 & 37.6 \\
\hline & 25 & -1.558 & 261 & 222 & 3.205 & 42.5 \\
\hline & 50 & -1.565 & 277 & 219 & 2.704 & 51.5 \\
\hline & 60 & -1.554 & 137 & 129 & 3.049 & 45.3 \\
\hline & 100 & -1.552 & 141 & 133 & 3.148 & 43.5 \\
\hline
\end{tabular}

The surface coverage $\theta$ is calculated as

$$
\theta=\frac{i_{\text {corr }_{(\text {(uninh) }}}-i_{\text {corr }_{\text {(inh) }}}}{i_{\text {corr }_{\text {(uninh) }}}}
$$

where $i_{\text {corr(uninh) }}$ and $i_{\text {corr(inh) }}$ are the corrosion current densities in the absence and presence of the inhibitor. The percentage of inhibition efficiency (\%IE) is given by

$$
\% I E=\theta \times 100
$$

Data from Table 2 reveal that the addition of EAMT decreases the corrosion of the alloy by decreasing the current density. The results show that the $\mathrm{E}_{\text {corr }}$ values shift to more negative potential as the concentration of added EAMT is increased, indicating a cathodic type of inhibition. Further inspection reveals that there is significant change in both anodic and cathodic Tafel slopes on the addition of EMAT. These results indicate that EAMT influences the dissolution 
of aluminium alloy and the hydrogen evolution process, indicating that the inhibitor behaved as a mixed - type corrosion inhibitor with predominant control of the cathodic reaction $[18,19]$. The corrosion current density is observed to be decreasing with increase in the concentration of the inhibitor, EAMT, up to a critical concentration. When the concentration of the inhibitor is increased above the critical concentration, the corrosion current density again increases. Accordingly, the inhibition efficiency of the inhibitor increases with the increase in the concentration of the inhibitor up to critical concentration level and then decreases with further increase in the inhibitor concentration. Experimental data pertaining to inhibition efficiency of EAMT suggest that the inhibition efficiency decreases with increase in temperature in all concentrations of sodium hydroxide solution and also at all inhibitor concentration levels (temperature data not shown in the paper).

\section{Electrochemical impedance spectroscopy (EIS) studies}

The corrosion behavior of the alloy in all the above conditions was also investigated by EIS method. Fig. 4 represents the Nyquist plots of the alloy without and with various concentrations of EAMT in $0.5 \mathrm{M} \mathrm{NaOH}$ at $30{ }^{\circ} \mathrm{C}$. Similar results were obtained in other concentrations of sodium hydroxide and also at other temperatures studied.

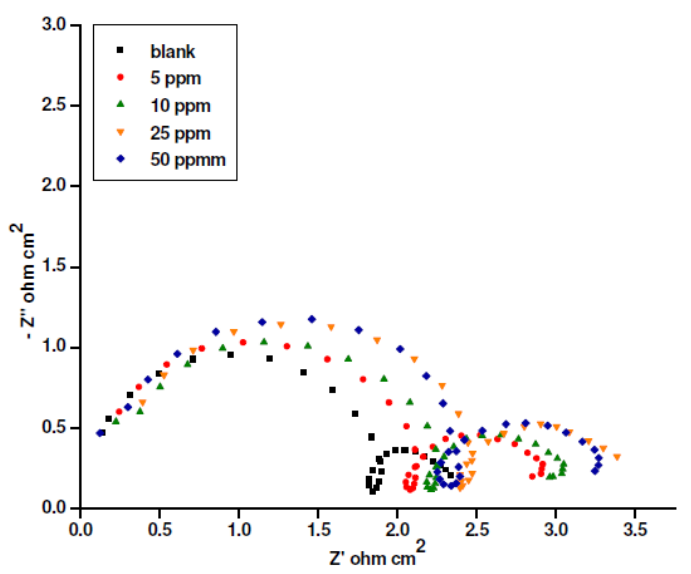

Figure 4. Nyquist plots for the corrosion of 6061-Al alloy in $0.5 \mathrm{M} \mathrm{NaOH}$ containing various concentrations of EAMT at $30{ }^{\circ} \mathrm{C}$.

As can be seen from Fig. 4, the impedance diagrams show semicircles, indicating that the corrosion process is mainly charge transfer controlled and the additives do not change the reaction mechanism of the corrosion of the alloy in sodium hydroxide solution. The figure manifests two depressed capacitive semicircles, separated by a small inductive loop at intermediate frequencies. The high frequency capacitive loop could be assigned to the charge transfer of the corrosion process and to the formation of oxide layer [20, 21]. The oxide film is considered to be a parallel circuit of a resistor due to the ionic conduction in the oxide film and a capacitor due to its dielectric properties. According to Brett [22, 23], the capacitive loop is corresponding to the interfacial reactions, particularly, the reaction of aluminum oxidation at the metal/oxide/electrolyte interface. The 
inductive loop may be related to the relaxation process obtained by adsorption of the intermediates [24-26]. The low frequency capacitive loop indicated the growth and dissolution of the surface film.

The impedance parameters derived from Nyquist plots and the inhibition efficiency of EAMT in sodium hydroxide solutions of different concentrations in the presence of EAMT at various concentrations, at $30{ }^{\circ} \mathrm{C}$, are given in Table 3 . Similar results were also obtained at other temperatures. The measured value of polarization resistance $\left(R_{p}\right)$ increases and the double layer capacitance decreases with the increasing concentration of EAMT in the solution, indicating decrease in the corrosion rate for the alloy with increase in EAMT concentration. This is in accordance with the observations obtained from potentiodynamic measurements.

Table 3. AC impedance data for the corrosion of $6061 \mathrm{Al}$ alloy at $30{ }^{\circ} \mathrm{C}$ in the presence of EAMT at different concentrations of sodium hydroxide solutions.

\begin{tabular}{|c|c|c|c|c|}
\hline $\begin{array}{c}\mathrm{NaOH} \\
\text { concentration } \\
\left(\text { mole } \mathrm{dm}^{-3}\right)\end{array}$ & $\begin{array}{c}\text { Inhibitor } \\
\text { concentration } \\
(\mathrm{ppm})\end{array}$ & $\begin{array}{c}R_{\mathrm{p}} \\
\left.(\mathrm{ohm} \mathrm{cm})^{2}\right)\end{array}$ & $C_{\mathrm{dl}}\left(\mathrm{F} \mathrm{cm}^{-2}\right)$ & $\% I E$ \\
\hline \multirow{7}{*}{0.05} & 0 & 3.87 & 0.0406 & - \\
\hline & 5 & 4.33 & 0.0419 & 10.5 \\
\hline & 10 & 4.59 & 0.0405 & 15.6 \\
\hline & 25 & 5.00 & 0.0390 & 22.6 \\
\hline & 50 & 5.52 & 0.0348 & 29.9 \\
\hline & 60 & 5.33 & 0.0376 & 27.3 \\
\hline & 100 & 4.89 & 0.0392 & 20.9 \\
\hline \multirow{7}{*}{0.1} & 0 & 1.84 & 0.0881 & - \\
\hline & 5 & 2.16 & 0.0745 & 15.1 \\
\hline & 10 & 2.21 & 0.0634 & 16.9 \\
\hline & 25 & 2.63 & 0.0563 & 30.2 \\
\hline & 50 & 3.06 & 0.0528 & 40.0 \\
\hline & 60 & 2.93 & 0.0546 & 37.2 \\
\hline & 100 & 2.75 & 0.0582 & 33.3 \\
\hline \multirow{7}{*}{0.25} & 0 & 0.75 & 0.1669 & - \\
\hline & 5 & 0.90 & 0.1348 & 16.9 \\
\hline & 10 & 0.99 & 0.1068 & 24.3 \\
\hline & 25 & 1.22 & 0.0999 & 38.5 \\
\hline & 50 & 1.27 & 0.0715 & 41.1 \\
\hline & 60 & 1.23 & 0.0945 & 39.4 \\
\hline & 100 & 1.20 & 0.1138 & 37.5 \\
\hline \multirow{7}{*}{0.5} & 0 & 0.61 & 0.2232 & - \\
\hline & 5 & 0.86 & 0.2148 & 28.6 \\
\hline & 10 & 0.92 & 0.1325 & 33.0 \\
\hline & 25 & 1.01 & 0.1158 & 39.3 \\
\hline & 50 & 1.11 & 0.0824 & 44.6 \\
\hline & 60 & 1.06 & 0.0991 & 42.1 \\
\hline & 100 & 1.00 & 0.1123 & 38.4 \\
\hline
\end{tabular}

The semicircles of the impedance spectra for the alloy are depressed. Deviation of this kind is referred to as frequency dispersion, and has been attributed to inhomogeneities of solid surfaces [27]. The impedance data were analyzed by using an equivalent circuit (EC) model consisting of six elements, as shown in Fig. 5. In this equivalent circuit, $R_{s}$ is the solution resistance, $R_{1}$ is the charge 
transfer resistance $\left(R_{c t}\right)$ and $L$ represents the inductive element. This also consists of constant phase element, $\mathrm{CPE}\left(\mathrm{C}_{2}\right)$ in parallel to the parallel resistor $\mathrm{R}_{2}$ and in series with $R_{1}$. There is also a capacitor element, $C_{1}$ in parallel with $R_{1}$ and $R_{2}$.

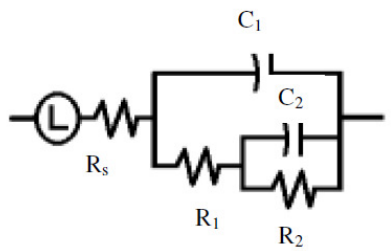

Figure 5. Electrochemical equivalent circuit used for simulation of impedance data for the corrosion of 6061-Al alloy in $0.5 \mathrm{M} \mathrm{NaOH}$.

In modeling the corrosion process, the capacitor usually behaves as a constant phase element $(\mathrm{CPE})$, rather than a pure capacitor [28,29]. The CPE impedance is given by [30]

$$
Z_{\mathrm{CPE}}=Y_{\mathrm{o}}^{-1}(j \omega)^{-n}
$$

where $Y_{0}$ is the CPE constant, $\omega$ is the angular frequency (in $\operatorname{rad~s}^{-1}$ ), $j^{2}=-1$ is the imaginary number and $\mathrm{n}$ is a CPE exponent which can be used as a measure of the heterogeneity or roughness of the surface. Depending on the value of $n$ ($1 \leq \mathrm{n} \leq 1)$, CPE describes an ideal capacitor for $\mathrm{n}=1$, an ideal inductor for $\mathrm{n}=-1$, and an ideal resistor for $\mathrm{n}=0$ [31,32]. $Y_{0}$ and $\mathrm{n}$ can be calculated by the equations proved by Mansfeld et al. [33].

The double layer capacitances $C_{\mathrm{dl}}$, for a circuit including CPE were calculated from the following equation [34]

$$
C_{\mathrm{dl}}=Y_{\mathrm{o}}\left(2 \pi f_{\max }\right)^{n-1}
$$

where $f_{\max }$ is the frequency at which the imaginary component of the impedance is maximal. The increase in $R_{\mathrm{p}}$ values, and consequently of the inhibition efficiency, shown in Table 3, supports the gradual replacement of water molecules by the adsorption of inhibitor molecules on the metal surface, and consequently leads to decrease in the number of active sites necessary for the corrosion process. The replacement of the water molecules by the inhibitor at metal/solution interphase within the electrical double layer increases the thickness of the barrier layer. According to the expression of the double layer capacitance presented in the Helmholtz model [35]

$$
C_{\mathrm{dl}}=\frac{\varepsilon \varepsilon_{\mathrm{o}}}{d} S
$$

where $\varepsilon_{\mathrm{o}}$ is the vacuum dielectric constant, $\varepsilon$ is the local dielectric constant, $d$ is the thickness of the double layer, and $S$ is the surface area of the electrode. It was observed that the total surface resistance calculated by fitting the experimental impedance data was increased, while the capacitance for the double layer decreased after the addition of EAMT, but not significantly, possibly because the protective film formed on the metal surface did not completely cover the metal surface. 
In accordance with the EC given in Fig. 4, the polarization resistance, $R_{\mathrm{p}}$, is given by:

$$
\mathrm{R}_{\mathrm{p}}=\mathrm{R}_{1}+\mathrm{R}_{2}
$$

The percentage of inhibition efficiency $\% I E$, was calculated from the following equation:

$$
\% I E=\left[\frac{\left(R_{p}\right)_{0}^{-1} /\left(R_{P}\right)^{-1}}{\left(R_{p}\right)_{0}^{-1}}\right]
$$

where $\left(R_{\mathrm{p}}\right)_{0}$ and $\left(R_{\mathrm{p}}\right)$ are the uninhibited and inhibited polarization resistances, respectively.

From the results of Tafel and EIS studies, it is seen that the inhibition efficiency trend in different sodium hydroxide concentrations is $0.5 \mathrm{M}>0.25 \mathrm{M}>0.1 \mathrm{M}>$ $0.05 \mathrm{M}$. The higher inhibition efficiency at higher concentrations of $\mathrm{NaOH}$ may be because the inhibitor ionizes more readily under higher alkaline conditions and is more easily adsorbed on the metal surface through active centers.

\section{Effect of the immersion time}

Electrochemical impedance spectroscopy is a rapid and useful technique to evaluate the performance of the organic-coated metals because it doesn't significantly disturb the system and it is possible to follow it overtime [29]. Therefore more reliable results can be obtained from this technique and also it is possible to characterize the surface modification, i.e., the formation and growth of the inhibitor film [36]. Immersion time experiments were carried out in 0.5 $\mathrm{M} \mathrm{NaOH}$ solution containing $50 \mathrm{ppm}$ of EAMT for 150 minutes at $30{ }^{\circ} \mathrm{C}$, and Nyquists plots were recorded every 5 min during the initial $30 \mathrm{~min}$, and then every $30 \mathrm{~min}$ afterward. The obtained results showed that the increase in immersion time increased the size of the capacitive loop, reaching a maximum in $60 \mathrm{~min}$ and remaining fairly constant afterward. In Fig. 6, the variation of both $\mathrm{R}_{\mathrm{p}}$ and $C_{\mathrm{dl}}$ with the immersion time recorded for $0.5 \mathrm{M} \mathrm{NaOH}$ solution is shown. Similar results were obtained for other concentrations of $\mathrm{NaOH}$ solutions also. It is obvious from the figure that $R_{\mathrm{p}}$ value increased from $1.113 \mathrm{ohm} \mathrm{cm}{ }^{2}$ to 1.4016 $\mathrm{ohm} \mathrm{cm}^{2}$, increasing the inhibition efficiency up to $56 \%$ during the initial $60 \mathrm{~min}$ and remaining fairly constant afterward. At the same time, $C_{\mathrm{dl}}$ values decreased up to $60 \mathrm{~min}$ and remained fairly constant thereafter. These results suggest that the formation of the inhibitive surface film on the electrode surface was almost completed within $60 \mathrm{~min}$. These results demonstrate that the inhibition efficiency increases with increasing the immersion time. This could be due to the progressive coverage of the metal alloy surface by the compact adsorbed film of the inhibitor, with time, the EMAT anions being electrostatically adsorbed on the metal surface. In order to ascertain the fact that the increase in $R_{p}$ value with time is due to the increased adsorption of the inhibitor and not due to the accumulation of the corrosion product, the immersion time experiment was repeated for the alloy in the absence of the inhibitor. The $R_{p}$ values did not vary significantly, indicating that there is no accumulation of the corrosion product on the alloy 
metal surface. This is expected as aluminium compounds are readily soluble in sodium hydroxide medium.

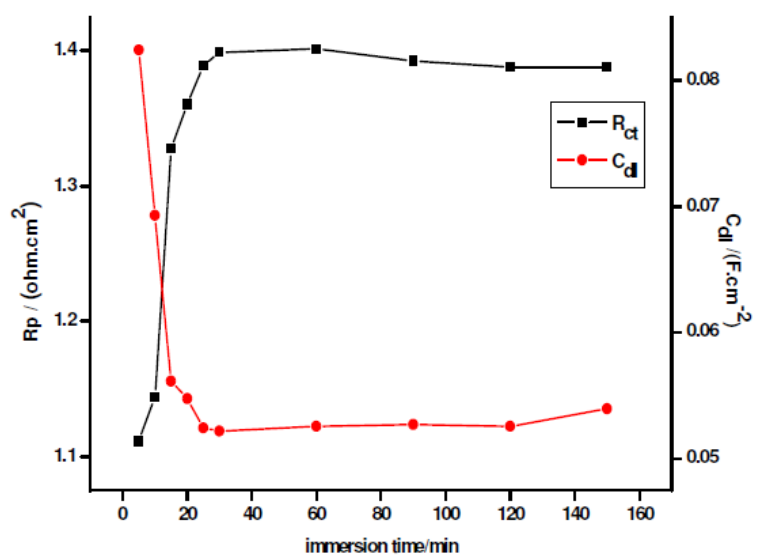

Figure 6. Dependence of $R_{\mathrm{p}}$ and $C_{\mathrm{dl}}$ on the immersion time for the corrosion of 6061-Al alloy in $0.5 \mathrm{M} \mathrm{NaOH}$ containing $50 \mathrm{ppm}$ of EAMT at $30{ }^{\circ} \mathrm{C}$.

\section{Adsorption behavior}

In order to understand the mechanism of corrosion inhibition, the adsorption behavior of the inhibitor molecules on the alloy surface must be known. It is well known the fact that the adsorption isotherms provide useful insights into the characteristics of the adsorption process and the mechanism of corrosion inhibition [37]. The degree of surface coverage $(\theta)$ at different concentrations of the inhibitor was evaluated from potentiodynamic polarization measurements. The data were tested graphically by fitting to various isotherms. The Langmuir adsorption isotherm was found to fit well with the experimental data, as shown in Fig. 6, and can be expressed as

$$
\frac{C}{\theta}=C+\frac{1}{K}
$$

where $K$ is the adsorption/desorption equilibrium constant, $C$ is the corrosion inhibitor concentration in the solution, and $\theta$ is the surface coverage. This adsorption is based on the assumption that all the adsorption sites are equivalent and that the particle binding occurs independently from the nearby sites being occupied or unoccupied [19].

The plots in Fig. 7 are linear, but the slopes are not equal to unity as would be expected for the ideal Langmuir adsorption isotherm equation. This deviation from unity may be due to the interaction among the adsorbed species on the metal surface. The polar groups or atoms present in the case of organic molecules are adsorbed at the anodic or cathodic sites of the metal surface. These adsorbed species may interact by mutual attraction or repulsion [38]. Thus, the inhibiting effect of EAMT molecules on metal surface in $\mathrm{NaOH}$ solution slightly deviates from ideal Langmuir adsorption isotherm. 


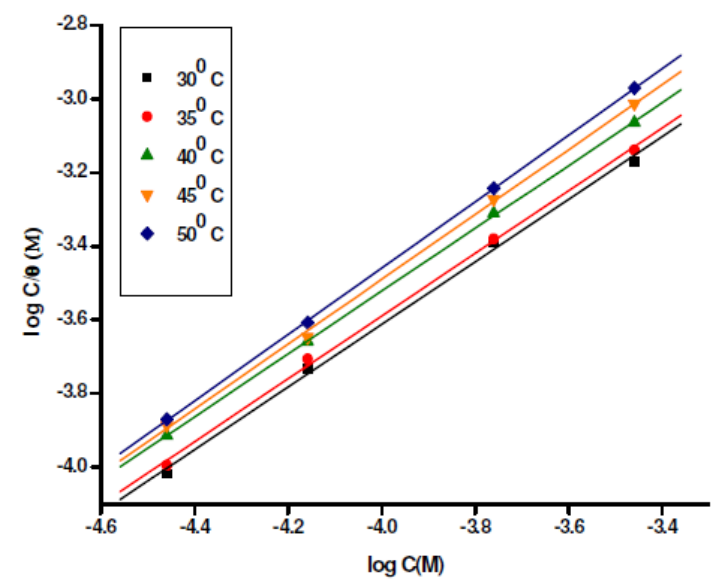

Figure 7. Langmuir adsorption isotherm for the adsorption of EAMT on the alloy surface.

Table 4. Thermodynamic parameters for the adsorption of EAMT on $6061 \mathrm{Al}$ alloy in $\mathrm{NaOH}$ solutions at different temperatures.

\begin{tabular}{|c|c|c|c|c|c|c|}
\hline $\begin{array}{c}\mathrm{NaOH} \\
\text { Concentration } \\
\left(\text { mole } \mathrm{dm}^{-3}\right)\end{array}$ & Temperature $\left({ }^{\circ} \mathrm{C}\right)$ & $\begin{array}{c}-\Delta G_{\text {ads }}^{\mathrm{o}} \\
\left(\mathrm{kJ} \mathrm{mol}^{-1)}\right.\end{array}$ & $\begin{array}{c}-\Delta H_{\mathrm{ads}}^{\mathrm{o}} \\
\left(\mathrm{kJ} \mathrm{mol}^{-1}\right)\end{array}$ & $\begin{array}{c}-\Delta S_{\text {ads }}^{\mathrm{o}} \\
\left(\mathrm{J} \mathrm{mol}^{-1} \mathrm{~K}^{-1}\right)\end{array}$ & $\log K$ & $\mathrm{R}^{2}$ \\
\hline \multirow{5}{*}{0.05} & 30 & 15.374 & \multirow{5}{*}{41.20} & \multirow{5}{*}{105.54} & 0.905 & 0.999 \\
\hline & 35 & 14.688 & & & 0.746 & 0.987 \\
\hline & 40 & 13.930 & & & 0.580 & 0.995 \\
\hline & 45 & 13.559 & & & 0.483 & 0.998 \\
\hline & 50 & 13.300 & & & 0.406 & 0.998 \\
\hline \multirow{5}{*}{0.1} & 30 & 17.382 & \multirow{5}{*}{110.49} & \multirow{5}{*}{303.38} & 1.252 & 0.977 \\
\hline & 35 & 17.429 & & & 1.211 & 0.999 \\
\hline & 40 & 17.205 & & & 1.126 & 0.986 \\
\hline & 45 & 14.360 & & & 0.614 & 0.987 \\
\hline & 50 & 11.332 & & & 0.088 & 0.977 \\
\hline \multirow{5}{*}{0.25} & 30 & 16.094 & \multirow{5}{*}{85.90} & \multirow{5}{*}{228.68} & 1.298 & 0.996 \\
\hline & 35 & 15.346 & & & 0.857 & 0.999 \\
\hline & 40 & 15.306 & & & 0.809 & 0.999 \\
\hline & 45 & 13.674 & & & 0.502 & 0.999 \\
\hline & 50 & 11.213 & & & 0.068 & 0.998 \\
\hline \multirow{5}{*}{0.5} & 30 & 11.346 & \multirow{5}{*}{20.25} & \multirow{5}{*}{29.30} & 0.212 & 0.999 \\
\hline & 35 & 11.295 & & & 0.171 & 0.999 \\
\hline & 40 & 11.085 & & & 0.105 & 0.999 \\
\hline & 45 & 10.842 & & & 0.036 & 0.999 \\
\hline & 50 & 10.840 & & & 0.009 & 0.999 \\
\hline
\end{tabular}

The thermodynamic parameter, free energy adsorption, $\left(\Delta G_{\text {ads }}^{o}\right)$ can be calculated from the following thermodynamic equation,

$$
K=\frac{1}{55.5} \exp \left(\frac{-\Delta G_{\text {ads }}^{\mathrm{o}}}{R T}\right)
$$

where $K$ is the equilibrium constant for the adsorption/desorption process, 55.5 mol dm${ }^{-3}$ is the molar concentration of water in the solution, $T$ is the temperature and $R$ is the gas constant. Standard enthalpy of adsorption $\left(\Delta H_{\text {ads }}^{o}\right)$ and standard 
entropy of adsorption ( $\left.\Delta S_{\text {ads }}^{o}\right)$ were obtained from the plot of $\left(\Delta G_{\text {ads }}^{\mathrm{o}}\right)$ versus $T$ according to the thermodynamic basic equation:

$$
\Delta G^{\mathrm{o}}{ }_{\text {ads }}=\Delta H^{\mathrm{o}}{ }_{\mathrm{ads}}-T \Delta S^{\mathrm{o}}{ }_{\mathrm{ads}}
$$

The values of free energy of adsorption $\left(\Delta G^{o}\right.$ ads $)$, enthalpy of adsorption $\left(\Delta H^{o}\right.$ ads $)$, entropy of adsorption $\left(\Delta S^{o}{ }_{\text {ads }}\right)$, equilibrium constant $(K)$ and linear correlation coefficient $\left(\mathrm{R}^{2}\right)$ obtained from the experimental data of potentiodynamic polarization method are given in Table 4 . The negative values of $\Delta G_{\text {ads }}^{o}$ imply the spontaneity of the adsorption process and stability of the adsorbed layer on the metal surface. Generally, the values of $\Delta G_{\text {ads }}$ lower than $-20 \mathrm{~kJ} \mathrm{~mol}^{-1}$ are consistent with physisorption, while those around $-40 \mathrm{~kJ} \mathrm{~mol}^{-1}$ or higher correspond to chemisorptions [39,40]. The calculated values of $\Delta G_{\text {ads }}^{\mathrm{o}}$ obtained in this study, indicate the physical adsorption behavior of EAMT on aluminium alloy metal surface. The negative values of $\Delta H^{\mathrm{o}}$ ads indicate that the adsorption of the inhibitor is an exothermic process. An exothermic adsorption process may involve either physisorption or chemisorption or a mixture of both processes [41]. The $\Delta S_{\text {ads }}^{\mathrm{o}}$ values in the presence of the inhibitor are negative, indicating that an increase in orderliness takes place on going from the free state to the adsorbed state of the inhibitors. This might be attributed to the orderly adsorption of the inhibitor molecules from a chaotic state of the freely moving molecules in the solution [42].

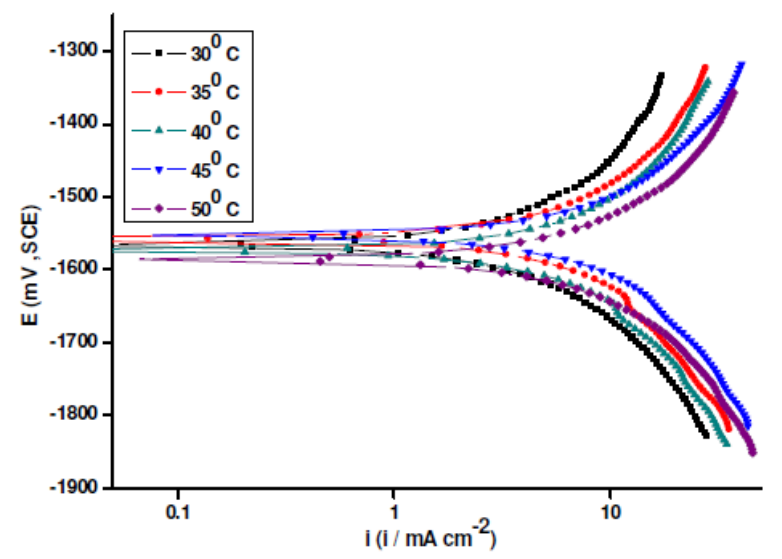

Figure 8. Tafel plots for the corrosion of 6061-Al alloy in $0.5 \mathrm{M}$ sodium hydroxide solution containing $50 \mathrm{ppm}$ of EAMT at different temperatures.

\section{Effect of temperature}

It was found that the inhibition efficiency of EAMT decreases with the increase in temperature. Fig. 8 represents the polarization curves for the corrosion of the base alloy in $0.5 \mathrm{M}$ sodium hydroxide solution in the presence of $50 \mathrm{ppm}$ EAMT at different temperatures. Similar results were obtained in the presence of other concentrations of the inhibitor and sodium hydroxide. Table 5 summarizes the Tafel polarization and impedance data for the corrosion of the alloy in $0.5 \mathrm{M}$ sodium hydroxide solution in the presence of different concentrations of EAMT at different temperatures. 
Table 5. Tafel extrapolation and EIS results for the corrosion of $6061 \mathrm{Al}$ alloy in 0.5 $M$ sodium hydroxide solution in the presence of different concentrations of EAMT at different temperatures.

\begin{tabular}{|c|c|c|c|c|c|c|c|c|c|}
\hline \multirow[b]{2}{*}{$\begin{array}{c}\mathrm{T} \\
\left({ }^{\circ} \mathrm{C}\right)\end{array}$} & \multicolumn{6}{|c|}{ Tafel } & \multicolumn{3}{|c|}{ EIS } \\
\hline & $\begin{array}{l}\text { Conc. } \\
\text { of inhibitor } \\
\text { (ppm) }\end{array}$ & $\begin{array}{c}\mathrm{E}_{\text {corr }} \\
(\mathrm{mV} / \mathrm{SCE})\end{array}$ & $\begin{array}{c}\mathrm{b}_{\mathrm{a}} \\
\left(\mathrm{mV} \mathrm{dec}{ }^{-1}\right)\end{array}$ & $\begin{array}{c}-\mathrm{b}_{\mathrm{c}} \\
\left(\mathrm{mV} \mathrm{\operatorname {dec } ^ { - 1 }}\right)\end{array}$ & $\begin{array}{c}\mathrm{i}_{\text {corr }} \\
\left(\mathrm{mA} \mathrm{cm}^{-2)}\right.\end{array}$ & $\begin{array}{c}\eta \\
(\%)\end{array}$ & $\begin{array}{c}\mathrm{R}_{\mathrm{p}} \\
\left(\mathrm{ohm} \mathrm{cm} \mathrm{cm}^{2} \text { ) }\right.\end{array}$ & $\begin{array}{c}\mathrm{C}_{\mathrm{dl}} \\
\left(\mathrm{F} \mathrm{cm}^{-2}\right)\end{array}$ & $\begin{array}{c}\mathrm{H} \\
(\%)\end{array}$ \\
\hline \multirow{5}{*}{30} & 0 & -1501 & 313 & 289 & 5.574 & - & 2.86 & 0.236 & \\
\hline & 5 & -1539 & 289 & 241 & 3.557 & 36.2 & 3.71 & 0.215 & 22.8 \\
\hline & 10 & -1545 & 276 & 233 & 3.479 & 37.6 & 3.89 & 0.133 & 26.3 \\
\hline & 25 & -1558 & 261 & 222 & 3.205 & 42.5 & 4.66 & 0.116 & 38.5 \\
\hline & 50 & -1565 & 257 & 219 & 2.705 & 51.5 & 5.26 & 0.083 & 45.5 \\
\hline \multirow{5}{*}{35} & 0 & -1492 & 323 & 293 & 6.097 & - & 2.24 & 0.254 & - \\
\hline & 5 & -1534 & 307 & 285 & 4.002 & 34.4 & 2.83 & 0.218 & 20.9 \\
\hline & 10 & -1545 & 295 & 299 & 3.930 & 35.4 & 2.96 & 0.158 & 24.3 \\
\hline & 25 & -1557 & 284 & 281 & 3.560 & 41.6 & 3.28 & 0.133 & 31.7 \\
\hline & 50 & -1560 & 279 & 280 & 3.184 & 47.8 & 4.01 & 0.088 & 44.0 \\
\hline \multirow{5}{*}{40} & 0 & -1496 & 308 & 281 & 6.628 & - & 2.04 & 0.264 & - \\
\hline & 5 & -1534 & 301 & 278 & 4.737 & 28.5 & 2.49 & 0.234 & 18.1 \\
\hline & 10 & -1542 & 297 & 275 & 4.530 & 31.7 & 2.60 & 0.200 & 21.5 \\
\hline & 25 & -1556 & 283 & 269 & 4.274 & 35.5 & 2.92 & 0.167 & 30.1 \\
\hline & 50 & -1574 & 281 & 263 & 3.958 & 40.3 & 3.30 & 0.161 & 38.3 \\
\hline \multirow{5}{*}{45} & 0 & -1481 & 262 & 265 & 7.037 & - & 1.75 & 0.505 & - \\
\hline & 5 & -1534 & 245 & 220 & 5.162 & 26.6 & 2.13 & 0.429 & 17.8 \\
\hline & 10 & -1542 & 189 & 197 & 4.875 & 30.7 & 2.16 & 0.374 & 19.0 \\
\hline & 25 & -1556 & 167 & 178 & 4.748 & 32.5 & 2.40 & 0.202 & 27.0 \\
\hline & 50 & -1574 & 162 & 164 & 4.521 & 35.8 & 2.57 & 1.878 & 31.8 \\
\hline \multirow{5}{*}{50} & 0 & -1496 & 320 & 359 & 8.983 & - & 1.45 & 0.526 & - \\
\hline & 5 & -1536 & 312 & 340 & 6.671 & 25.7 & 1.64 & 0.495 & 11.5 \\
\hline & 10 & -1542 & 307 & 298 & 6.456 & 28.1 & 1.78 & 0.458 & 18.5 \\
\hline & 25 & -1556 & 299 & 266 & 6.255 & 30.4 & 1.86 & 0.255 & 22.2 \\
\hline & 50 & -1564 & 273 & 258 & 6.071 & 32.4 & 1.97 & 0.234 & 26.5 \\
\hline
\end{tabular}

Corrosion reactions are usually regarded as Arrhenius processes and the corrosion rate can be expressed by the relation:

$$
C R=k \exp \left(\frac{-E_{\mathrm{a}}}{R T}\right)
$$

where $\mathrm{k}$, the Arrhenius pre-exponential constant, depends on the metal type and electrolyte, $E_{\mathrm{a}}$ is the activation energy of the corrosion process, $R$ is the universal gas constant and $T$ is the absolute temperature. Plot of $\ln C R$ vs. $1 / T$ for the 6061 Al alloy in $0.5 \mathrm{M} \mathrm{NaOH}$ solution in the absence and presence of various concentrations of EAMT is shown in Fig. 9.

The values of $\Delta H_{\mathrm{a}}$ and $\Delta S_{\mathrm{a}}$ were calculated from the plot of $\ln C R / T$ vs. $1 / T$ for base alloy in $0.5 \mathrm{M} \mathrm{NaOH}$ solution (Fig. 10) in the absence and presence of various concentrations of EAMT according to transition state equation:

$$
C R=\frac{R T}{N h} \exp \left(\frac{\Delta S_{\mathrm{a}}}{R}\right) \exp \left(\frac{-\Delta H_{\mathrm{a}}}{R}\right)
$$

where $\mathrm{h}$ is Planck's constant, $\mathrm{N}$ is Avogadro's number, $\Delta H_{\mathrm{a}}$ is the activation enthalpy and $\Delta \mathrm{S}_{\mathrm{a}}$ is the activation entropy. The calculated values of the apparent 
activation energy $E_{\mathrm{a}}$, activation enthalpies $\Delta \mathrm{H}_{\mathrm{a}}$, and activation entropies $\Delta \mathrm{S}_{\mathrm{a}}$, are given in Table 6 . The increase in the activation energies with increasing concentration of the inhibitor is attributed to physical adsorption of the inhibitor molecules on the metal surface [43], with an appreciable increase in the adsorption process of the inhibitor on the metal surface with increasing in the concentration of inhibitor. The negative values of the entropy of activation, $\Delta S_{a}$, in the blank and inhibited solutions, imply that the activated complex is the rate determining step and represents association rather than dissociation. It also reveals that an increase in the order takes place in going from reactants to the activated complex [43].

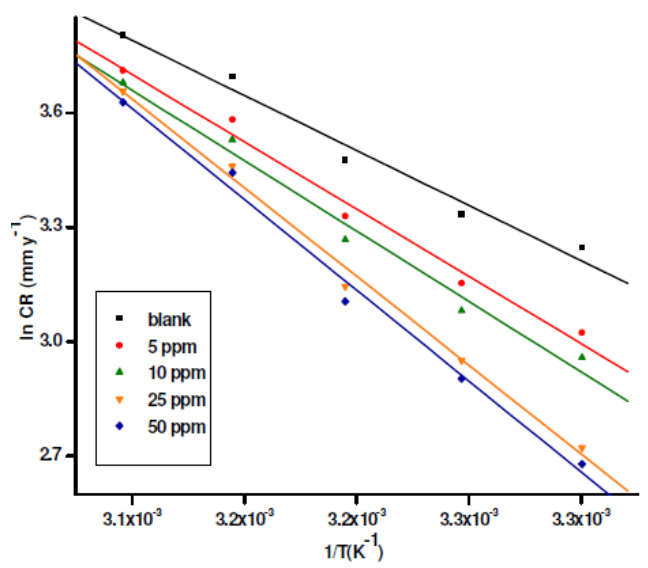

Figure 9. Variation of $\ln (C R)$ vs. $1 / T$ for the corrosion of 6061-Al alloy in $0.5 \mathrm{M}$ $\mathrm{NaOH}$ in the presence of different concentrations of EAMT.

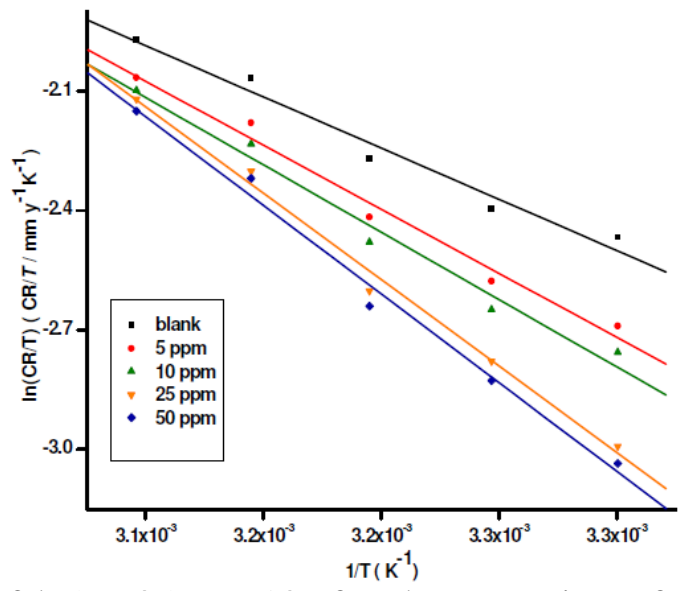

Figure 10. Variation of $\ln (C R / T)$ vs. $1 / T$ for the corrosion of 6061-Al alloy in $0.5 \mathrm{M}$ $\mathrm{NaOH}$ in the presence of different concentrations of EAMT.

\section{Scanning Electron Microscopy}

In order to evaluate the conditions of the $6061 \mathrm{Al}$ alloy surface in contact with alkaline solution, a surface analysis was carried out. The SEM micrograph of the corroded specimen after 1 hour of immersion in $0.5 \mathrm{M} \mathrm{NaOH}$ solution is shown in Fig. 11 (a). The faceting seen in the figure is due to the attack of aggressive hydroxide ions, the specimen has undergone more or less uniform corrosion. Fig. 11 (b) depicts the SEM of specimen after 1 hour of immersion in $0.5 \mathrm{M} \mathrm{NaOH}$ 
solution with the addition of $50 \mathrm{ppm}$ EAMT. It can be seen that the flakes in the surface of the specimen are reduced when compared with the micrograph given in Fig. 11 (a). The specimen surface can be observed to be covered with a thin layer of the inhibitor molecules, giving protection against corrosion. It is also interesting to note the presence of some defective sites due to the break down of the film, which permits a free access of aggressive ions to the metal surface.

Table 6. Activation parameters for the corrosion of $6061 \mathrm{Al}$ alloy in $\mathrm{NaOH}$ solution in the absence and presence of different concentrations of EAMT.

\begin{tabular}{|c|c|c|c|c|c|}
\hline \multirow{2}{*}{$\begin{array}{c}\mathrm{NaOH} \\
\text { concentration } \\
\left(\text { mole } \mathrm{dm}^{-3}\right)\end{array}$} & \multicolumn{5}{|c|}{$\mathrm{E}_{\mathrm{a}}\left(\mathrm{kJ} \mathrm{mol}^{-1}\right)$} \\
\hline & blank & $5 \mathrm{ppm}$ & 10ppm & $25 \mathrm{ppm}$ & 50ppm \\
\hline 0.05 & 41.24 & 44.28 & 45.75 & 48.04 & 51.81 \\
\hline 0.1 & 30.99 & 33.32 & 34.38 & 40.56 & 45.12 \\
\hline 0.25 & 23.99 & 28.42 & 30.71 & 38.69 & 39.62 \\
\hline 0.5 & 17.79 & 24.56 & 23.55 & 26.38 & 30.53 \\
\hline \multicolumn{6}{|c|}{$\Delta H_{\mathrm{a}}\left(\mathrm{kJ} \mathrm{mol}^{-1}\right)$} \\
\hline 0.05 & 38.64 & 41.68 & 43.16 & 45.44 & 49.21 \\
\hline 0.1 & 28.39 . & 30.72 & 31.78 & 37.96 & 42.52 \\
\hline 0.25 & 21.39 & 25.82 & 28.12 & 36.09 & 37.02 \\
\hline 0.5 & 15.19 & 21.96 & 20.96 & 23.77 & 27.93 \\
\hline \multicolumn{6}{|c|}{$-\Delta S_{\mathrm{a}}\left(\mathrm{J} \mathrm{mol}^{-1} \mathrm{~K}^{-1}\right)$} \\
\hline 0.05 & 74.05 & 73.00 & 72.46 & 71.67 & 70.28 \\
\hline 0.1 & 77.45 & 76.68 & 76.32 & 74.03 & 72.39 \\
\hline 0.25 & 79.64 & 78.08 & 77.27 & 74.32 & 73.99 \\
\hline 0.5 & 81.23 & 78.99 & 79.41 & 78.38 & 76.88 \\
\hline
\end{tabular}
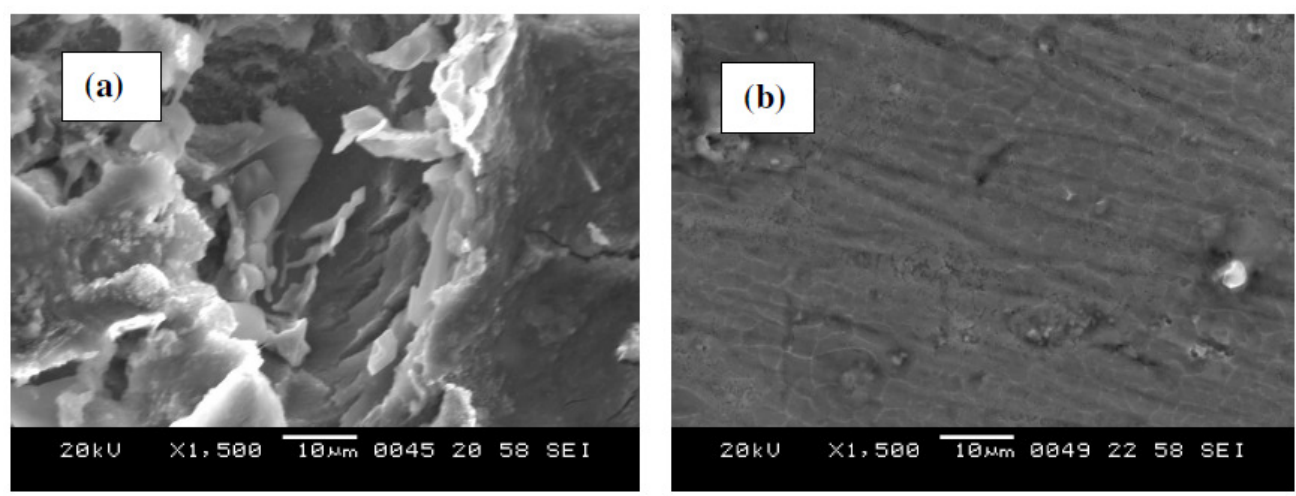

Figure 11. SEM images of the surface of 6061-Al alloy after immersion for $1 \mathrm{~h}$ in 0.5 $\mathrm{M} \mathrm{NaOH}$ solution at $30{ }^{\circ} \mathrm{C}$, (a) in the absence of EAMT, (b) in the presence of $50 \mathrm{ppm}$ EAMT.

\section{Inhibition mechanism}

Generally, the adsorption of organic molecules on metallic surfaces involves oxygen, nitrogen and sulphur atoms as active centres, forming the linkages with the metal surface. The good inhibition efficiency of EAMT is attributed to strong adsorption of inhibitor species on the metal surface through the active centers, nitrogen and sulphur atoms. In $\mathrm{NaOH}$ solution EAMT exits in the ionized form, as shown in Fig. 12. 


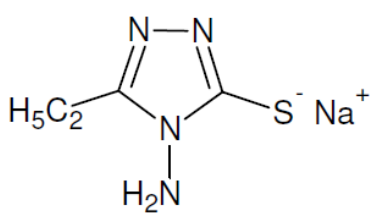

Figure 12. Ionized form of EAMT in aqueous $\mathrm{NaOH}$ solution.

The presence of ethyl group with $+\mathrm{R}$ (resonance) and $+\mathrm{I}$ (inductive) effects in the heterocyclic ring has a marked effect on the inhibition efficiency of the triazole molecule. A substituted ethyl group at the position 3 would donate charge through hyperconjugation and by the inductive effect, thus concentrating the charge density on nitrogen and sulphur atoms, thereby increasing their adsorption at the anodic sites of the metal which would normally suffer anodic attack. In the presence of aggressive hydroxide ions, it is assumed that the inhibitor anions with high charge density compete with anions such as $\mathrm{OH}^{-}$ions and preferentially adsorbed at the anodic sites of the metal surface. Adsorption of the inhibitor at the metal surface replaces the water molecules within the electrical double layer to produce less pronounced dielectric effect [18] and thus holds up the reaction of surface water molecules, thus the rate of hydrogen evolution is reduced, thereby effecting the cathodic reactions.

\section{Conclusions}

-The corrosion studies of the 6061 aluminium alloy was carried out at 30 to $50{ }^{\circ} \mathrm{C}$ temperatures using $\mathrm{NaOH}$ solutions, and the results indicate that EAMT improved the corrosion resistance of the alloy in alkaline environment.

- The potentiodynamic polarization curves suggested a mixed-type with a predominant control of the cathodic reaction for the inhibition process in $\mathrm{NaOH}$ solution.

- The inhibition efficiency increases with the increase in the $\mathrm{NaOH}$ concentration.

- The inhibition efficiency decreases with the increase in temperature.

- The adsorption of EAMT on the metal surface follows Langmuir adsorption isotherm.

- The inhibition efficiencies obtained from potentiodynamic polarization and EIS techniques are in reasonably agreement.

\section{References}

1. M.L. Doche, J.J. Rameau, R. Durand and F. Novel-Cattin, Corros. Sci. 41 (1999) 805.

2. Sung-Mo Moon, Su-II Pyun, Electrochim. Acta 44 (1999) 2445.

3. H. Scholl, M.M.D. Jimenez, Corros. Sci. 33 (1992) 1967.

4. A.S. Fouda, A.A. AI-Sarawy, F. Sh. Ahmed, H.M. EI-Abbasy, Corros. Sci. 51 (2009) 485.

5. P. Nitin Wasekar, A. Jyothirmayi, L. Ramakrishna and G. Sundararajan, JMEPEG 17 (2008) 708. 
6. J. Davis, Corrosion Understanding the Basics, ASM International, (2000) USA.

7. F.M. AI-Kharafi, W.A. Badawy, Corrosion 5 (1997) 377.

8. J.D. Talati, R.M. Modi, Corros. Sci. 19 (1979) 35.

9. G. Bereket, A. Pinarbasi, Corros. Eng. Scie. Techn. 39 (2004) 308.

10. E.E. Oguzie, B.N. Okolue, C.E. Ogukwe, C. Unaegbu, Materials Letters 60 (2006) 3376.

11. A.K. Satpati, P.V. Ravindran, Mater. Chem. Phys. 109 (2008) 352.

12. V. Branzoi, F. Golgovici, F. Branzoi, Mater. Chem. Phys. 78 (2002) 122.

13. M.N. Moussa, A.S. Fouda, F.I. Taha, A. Elnenaa, Bull. Korean Chem. Soci. 9 (1998) 191.

14. Z. Grubac, R. Babic, Metikos-Hukovic, J. Appl. Electrochem. 32 (2002) 431.

15. S.S. Abd EI Rehim, H.H. Hassan, A.M. Amin, Mater. Chem. Phys. 78 (2002) 337.

16. M. Abdallah, Corros. Sci. 46 (2004) 1981.

17. P.T. Shah, T.C. Daniels, Rev. Trav. Chim. 69 (1950) 1545.

18. A.R. Yazdad, T. Shahrabi, M.G. Hosseini, Mater. Chem. Phys.109 (2008) 199.

19. R. Rosliza, W.B. Wan Nik, Current Applied Phys. 10 (2010) 221.

20. F. Mansfeld, S. Lin, S. Kim, H. Shih, Corros. Sci. 27 (1987) 997.

21. F. Mansfeld, S. Lin, S. Kim, H. Shih, U. West, Korros. 39 (1988) 487.

22. C.M.A. Brett, J. Appl. Electrochem. 20 (1990) 1000.

23. C.M.A. Brett, Corros. Sci. 33 (1992) 203.

24. H.J.W. Lenderink, M.V.D. Linden, J.H.W. De Wit, Electrochim. Acta. 38 (1993) 1989.

25. D.D. Macdonald, S.S. Real, S.I. Smeldley, M. Urquidi-Macdonald, J. Electrochem. Soc. 135 (1988) 2410.

26. M. Paramasivam, G. Suresh, B. Muthuramalingam, S. Venkatakrishna Iyer, V. Kapali, Appl. Electrochem. 21 (1990) 452.

27. K. Juttner, Electrochim. Acta. 35 (1990) 1501.

28. A.A. Mohammed, K.F. Khaled, Q. Mohsen, H.A. Arida, Corros. Sci. 52 (2010) 1684.

29. I. Dehri, M. Erbil, Corros. Sci. 42 (2000) 969.

30. U. Rammelt, S. Kohler, G. Reinhard, Electrochim. Acta. 53 (2008) 6968.

31. A.K. Mishra, R. Balasubramaniam, Mater. Chem. Phys. 103 (2007) 385.

32. A.K. Singh, M.A. Quraishi, Corros. Sci. 52 (2010) 1373.

33. F. Mansfeld, C.H. Tsai, H. Shih, In: Munn RS (ed.), Computer modelling in corrosion. ASTM, Philadelphia, 1992.

34. C.H. Hsu, F. Mansfeld, Corrosion 57 (2001) 747.

35. E. McCafferty, N. Hackerman, J. Electrochem. Soc. 119 (1972) 146.

36. R. Solmaz, G. Kardas, M. Culha, B. Yazici, M. Erbil, Electrochim. Acta 53 (2008) 5941.

37. W. Durnie, R. De Marc, R. Jefferson, B. Kinsella, J. Electrochem. Soc. 146 (1990) 1751.

38. A.P. Bansiwal, P. Anthony, S.P. Mathur, Br. Corros. J. 4 (2000) 301. 
39. S.A. Umoren, E.E. Ebenso, P.C. Okafor, U.J. Ekpe, O. Ogbobe, J. Appl. Polym. Sci. 103 (2007) 2810.

40. S.A. Ali, EI-Sherif, R.F. AI-Ghamdi, M.T. Saeed, Corros. Sci. 47 (2005) 2659.

41. A.A. Khadom, A.S. Yaro, A.S. AlTafie, A.A.H. Kadum, Port. Electrochim. Acta 27 (2009) 699.

42. L. Tang, G. Mu, G. Liu, Corros. Sci. 45 (2003) 2251.

43. H. Ashassi-Sorkhabi, Z. Ghasemi, D. Seifzadeh, Appl. Surf. Sci. 249 (2005) 408. 